\title{
Factors Associated with Childhood Depression in Saskatoon Students: A Multilevel Analysis
}

\author{
Shan Jin and Nazeem Muhajarine \\ University of Saskatchewan \\ Jennifer Cushon \\ Public Health Observatory, Saskatoon Health Region \\ Hyun J. Lim \\ University of Saskatchewan
}

\begin{abstract}
This study examined links between depression and multilevel factors among children from Saskatoon elementary schools. A total of 4,200 students participated in the Saskatoon Student Health Survey conducted in 2008-9. Covariates included demographics and family structure, relationships, physical activity, bullying experiences, and school refusal behaviours. A multilevel logistic regression model was used to examine the impact of individual-level and school-level (contextual) factors. The study revealed that depression disparity existed among schools, and students' school refusal behaviours such as skipping or being suspended from school were among the main factors contributing to the disparity between schools.
\end{abstract}

Keywords: Childhood depression, multilevel model, physical activity, bullying, school refusal behaviours

\section{RÉSUMÉ}

Cette étude nous a permis d'analyser les liens entre différents facteurs et la dépression chez les enfants qui fréquentent l'école élémentaire, grâce aux données d'une étude sur la santé menée auprès de 4200 enfants en 2008-2009 à Saskatoon (la Saskatoon Student Health Survey). Les covariables que nous avons

\footnotetext{
Shan Jin, Department of Community Health and Epidemiology, College of Medicine, University of Saskatchewan. Nazeem Muhajarine, Department of Community Health and Epidemiology and Saskatchewan Population Health and Evaluation Research Unit, College of Medicine, University of Saskatchewan. Jennifer Cushon, Public Health Observatory, Saskatoon Health Region. Hyun J. Lim, Department of Community Health and Epidemiology, College of Medicine, University of Saskatchewan.

Correspondence regarding this paper should be directed to Hyun J. Lim, Department of Community Health and Epidemiology, College of Medicine, University of Saskatchewan, 107 Wiggins Road, Saskatoon, SK S7N 5E5. Tel: 306-966-6288. Fax: 306-9667920. E-mail: hyun.lim@usask.ca
} 
examinées sont les suivantes : des facteurs démographiques, la structure familiale, les relations avec les parents, l'activité physique, le fait d'avoir subi de l'intimidation et des comportements liés au refus scolaire. Nous avons utilisé un modèle de régression logistique à plusieurs niveaux pour analyser l'impact des différents facteurs qui agissent soit au niveau individuel soit au niveau collectif (l'école). Nos résultats montrent que la situation n'est pas la même dans toutes les écoles, et que ces différences sont principalement dues à des comportements liés au refus scolaire (faire l'école buissonnière ou être suspendu de l'école, par exemple).

Mots clés : dépression infantile, modèle à plusieurs niveaux, activité physique, intimidation, refus scolaire

Mental health is an essential component in children's development and yet it is one of the most underevaluated and under-appreciated developmental domains in children's health (Stagman \& Cooper, 2010). It is widely and readily accepted that robust and stable mental health is essential for the health and well-being of children now and in the future. A national survey of school-aged youth in the United States revealed evidence of many mild and moderate forms of mental disorders in children, indicating that more than $12 \%$ of children under the age of 18 had experienced mental disorder problems (National Institute of Mental Health, 1990; Tuma, 1989).

Several longitudinal studies of self-reported depression have found that the level or intensity of depression increases from a relatively lower level in childhood to a higher level in adolescence (Cole, Martin, Peeke, Seroczynski, \& Fier, 1999; Ge, Lorenz, Conger, Elder, \& Simons, 1994; Wade, Cairney, \& Pevalin, 2002; Wichstrom, 1999). Furthermore, it has also been reported that depression in adulthood is usually preceded by depression in youth (Kim-Cohen et al., 2003). For all these reasons, an examination of childhood depression is not only warranted but also timely for a more well-rounded understanding of population health in Canada.

Depression is a multi-factorial disorder associated with many factors. First, studies have suggested that physical activity is linked to positive mental health status. Individuals with depressive symptoms tended to be less physically active, and increased exercise was shown to reduce depression (Martinsen, 1990; Paluska $\&$ Schwenk, 2000; Sallis, 1996). Second, bullying is defined as repeated aggression among peers, in which one or more people intend to harm another person physically, verbally, or socially (Boulton \& Underwood, 1992; Nansel et al., 2001; Olweus, 1978; Wolke, Woods, Stanford, \& Schulz, 2001). Children who had been directly or indirectly bullied were more likely to experience depression and anxiety (Arseneault et al., 2006; Craig, 1998; Crick \& Bigbee, 1998; Hawker \& Boulton, 2000; Hodges \& Perry, 1999). In one study it was found that among children with school refusal behaviour (defined as children who skip or refuse to attend school), 50\% of the participants met the criteria for severe depression (Kearney, 2007).

Aboriginal children are more likely to experience poor health outcomes in Canada (Health Canada, 2003). However, the 2006-2007 Saskatoon Student Health Survey found that Aboriginal children were no more likely to report depressed mood than Caucasian children after adjusting for SES (Lemstra \& Neudorf, 2008).

School is an essential factor in children's mental health status because they spend more than one third of their time and engage in numerous social interactions at school. Individual behaviours, such as children's school refusal behaviour, can be affected by characteristics of the school, including school policies, composition, and location (Anderman, 2002; Opdenakker \& Van Damme, 2001; Trautwein, Köller, Schmitz, 
\& Baumert, 2002). Most previous studies have concentrated on school-related outcomes rather than school contextual and compositional effects; hence, there have been few studies focused on depressive symptoms in children in relation to school contextual effects (Ellonen, Kaariainen, \& Autio, 2008).

Area-level deprivation is another school contextual effect that has not been extensively explored in the literature. The concept of deprivation, as used in many studies, is related to poverty, but it is not necessarily synonymous with poverty since poverty is often measured only in terms of income (Boyle, Gatrell, \& Duke-Williams, 2001; Jones \& Duncan, 1995; Kobetz, Daniel, \& Earp, 2003; Malmström, Johansson, \& Sundquist, 2001; Ross, 2000; Stafford \& Marmot, 2003). Theoretically, it has been suggested that the distressing effects of neighbourhood poverty and deprivation on individuals work through the invocation and internalization of neighbourhood physical and social problems (Ross, 2000). In our study, deprivation is considered as having two aspects: material deprivation and social deprivation. Material deprivation is measured with reference to education, employment, and income, while social deprivation is associated with single parenting, marital status, and living alone (Pampalon \& Raymond, 2000)

The primary aims of this study were: (a) to examine whether depression varies among Saskatoon elementary schools, and (b) to identify multilevel factors that are associated with depression among Saskatoon students. In the next section, we introduce the study description and statistical approaches used in the analysis. Then the results of the analysis are presented. The final section contains a discussion of results, program implications, and study limitations, followed by a conclusion.

\section{METHOD}

\section{Study Population}

Every elementary school student in Grades 5-8 in Saskatoon was asked to complete the Student Health Survey in September 2008. There were 9,370 children registered in these grades. Consent was obtained from parents and children. In total, 4,200 students in Grades 5-8 took part in the survey, representing a response rate of $44.8 \%$. The survey was administered by the classroom teacher. Seventy-six Saskatoon elementary schools participated in the survey. The Saskatoon Health Region uses the Student Health Survey to plan programming and services. The survey was mainly focused on mental health, physical activity, and bullying. School-level information on material deprivation and social deprivation was obtained from Saskatoon Health Region. Deprivation in our study was a school contextual variable which means it did not reflect the deprivation situation of each individual, but reflected the general deprivation status of each school.

\section{Measures}

The 2008-2009 Student Health Survey contained 114 items. Table 1 presents all the variables that were taken into account in our study, as well as their definitions and source of data. Most items were drawn from other validated surveys. First, the Center for Epidemiologic Studies Depression Scale-12 (CES-D-12) was used to assess self-reported depression among participants. Subjects who reported a total score of 11 or higher out of a possible 36 were considered to have a moderate or severe depressed mood (Statistics Canada, 2002). Poulin, Hand, and Boudreau (2005) found that the CES-D-12 has an internal consistency of 
0.85. All items but one on the CES-D-12 ("I felt hopeful about the future") have acceptable discrimination ability (Poulin et al., 2005).

Physical activity measures were from the School Health Action Planning and Evaluation System's (SHAPES) Physical Activity and Physical Activity Stages Questionnaires (PASCQ). Students were asked to recall the number of hours that each type of physical activity was performed for each day of the previous week (Wong, Leatherdale, \& Manske, 2006).

The number of kilocalories expanded per kilogram of body weight per day (KKD) was then calculated to determine the level of participants' physical activity. Physical activity level was calculated as the sum of KKD of both hard and moderate physical activity divided by the number of days. Total KKD was divided into three categories: KKD $<3$ for inactive, $3 \leq \mathrm{KKD}<8$ for moderately active, KKD $\geq 8$ for very active.

Body Mass Index (BMI) was calculated using self-reported height and weight information. The Centers for Disease Control and Prevention Body Mass Index for Age Percentiles Charts for boys and girls 2-20 years of age were used to determine the students' BMI by age (Centers for Disease Control and Prevention, 2010). BMIs ranging from 25 to 29.9 were considered overweight, and BMIs of 30 or greater were considered obese.

Bullying questions were extracted from the Safe School Survey (Canadian Public Health Association \& National Crime Prevention Strategy, 2007). The eight-question parenting relationship scale, which came from the Health Behaviour in School-Age Children (HBSC) survey, estimates the relationship between children and their parents (Boyce, 2004). Questions related to peer group and friendship originated from the National Longitudinal Survey of Children and Youth (Statistics Canada, 2002). Questions about the frequency of being suspended from school and skipping school (i.e., school refusal behaviours) were developed by the Saskatoon Health Region.

The deprivation index has been developed to measure the level of deprivation. The deprivation index of Canada contains 47,464 dissemination areas (DAs), with a population of 400 to 700 persons in each DA. This index includes approximately $98 \%$ of the population of Canada. The DAs were ranked from the most to the least privileged, and then broken down into quintiles, each of which contains $20 \%$ of the total population. Quintile 1 represents the most privileged population while quintile 5 represents the most deprived (Pampalon, Hamel, Gamache, \& Raymond, 2009). In our study, each school reported the number of students in each deprivation quintile. A deprivation level for each school was calculated as the number of students in quintile 4 and quintile 5 out of the total number of students, and schools were then divided into three categories: $<20 \%$ as minimum deprivation (most privilege), $20 \%-80 \%$ as moderate deprivation, and $>80 \%$ as maximum deprivation.

\section{Data Analysis}

Descriptive statistics were used to summarize the data. Univariate, multivariate, and multilevel logistic regression models were built. A multilevel modelling approach was considered appropriate for this study since groups of students that come from the same elementary school were considered clustered, rather than independent from one another. To investigate the study questions (examining whether depression varies among schools, and identifying multilevel factors that are associated with depression among students), a four-step approach was adopted. The initial step was to build a null model. A null model is a multilevel model with 
Table 1

Variables and Measurements

\begin{tabular}{|c|c|c|}
\hline Variable & Definition & Source of data \\
\hline \multicolumn{3}{|l|}{ Demographic } \\
\hline Gender & What is your gender? & Self-report \\
\hline Age & How old are you? & Self-report \\
\hline Cultural Status & What is your cultural status? & Self-report \\
\hline Whom do you live with? & Whom do you live with? & Self-report \\
\hline Relationship with parents & How is your relationship with your parents? & $\begin{array}{l}\text { 8-question scale } \\
\text { from HBSC }\end{array}$ \\
\hline Parents' education level & What is your parents' education level? & Self-report \\
\hline Parents' job & Does your parents have job? & Self-report \\
\hline \multicolumn{3}{|l|}{ Physical activity } \\
\hline Days go to gym class & How often do you go to gym classes? & Self-report \\
\hline Off-school activity & How often do you participate in activities out of school? & Self-report \\
\hline Physical activity & $\begin{array}{l}\text { How many minutes of hard/moderate physical activity } \\
\text { did you do on each of the last } 7 \text { days? }\end{array}$ & SHAPES \& PASCQ \\
\hline BMI & What is your Body Mass Index? & Weight $/$ height $^{2}$ \\
\hline \multicolumn{3}{|l|}{ Bullying } \\
\hline Physical bullying & $\begin{array}{l}\text { How often have you been bullied by other students } \\
\text { physically last month? }\end{array}$ & Self-report \\
\hline Verbal bullying & $\begin{array}{l}\text { How often have you been bullied by other students } \\
\text { verbally last month? }\end{array}$ & Self-report \\
\hline Social bullying & $\begin{array}{l}\text { How often have you been bullied by other students } \\
\text { socially last month? }\end{array}$ & Self-report \\
\hline Electronic bullying & $\begin{array}{l}\text { How often have you been bullied by other students } \\
\text { electronically last month? }\end{array}$ & Self-report \\
\hline Bullying & $\begin{array}{l}\text { How often have you been bullied by other students last } \\
\text { month? }\end{array}$ & Self-report \\
\hline \multicolumn{3}{|l|}{ School performance } \\
\hline Have many friends & Do you have many friends at school? & Self-report \\
\hline Get along with others & Do you get along with others of your age? & Self-report \\
\hline Feel like an outsider & How often do you often feel like an outsider? & Self-report \\
\hline Skipped school & How many times have you skipped a day of school? & Self-report \\
\hline Suspended & How many times have you been suspended from school? & Self-report \\
\hline Treated badly at school & Have you been treated badly at school? & Self-report \\
\hline \multicolumn{3}{|l|}{ Deprivation } \\
\hline Material deprivation & Material deprivation level of your school & Deprivation Index \\
\hline Social deprivation & Social deprivation level of your school & Deprivation Index \\
\hline
\end{tabular}


only random effects in it as independent variables. This null model can tell us whether the random effects have an impact on the outcome. The random effect in our study is school; thus our null model was used to determine whether there was depression disparity between schools. The second step was to add adjusted variables including demographic characteristics and family structure into the model. For the third step, main risk factors including physical activity, bullying, and school refusal behaviour were added to the model. Finally, a full model was achieved by adding a contextual variable (school deprivation) as a school-level fixed effect. The final model contained explanatory variables at both individual and school levels. Multilevel models take into account the variability at each level of the hierarchy, students and schools, and account for students clustered within schools. Variables were identified as significant using a $0.05 \alpha$-level. SAS software version 9.2 was used for data analysis.

\section{RESULTS}

\section{Descriptive Results}

Of 4,200 children, there were 3,648 (86.9\%) who responded to the questions about depression. Most of the children who responded to the depression questions were between 11 and 13 (80\%), and the majority were of Caucasian background (78.2\%). Of the 3,648 students, $80 \%$ had a normal BMI. Of those who responded to the depression questions, $813(22.3 \%)$ reported suffering from moderate or severe depressed mood. The results showed that girls had a higher rate of depression than boys. Children who did not live with both parents, those whose parents' educational levels were low, and those who had a "very good relationship" with their parents reported having a higher prevalence of depression. Those who had a low level of physical activity and who were overweight also reported having a higher prevalence of depression. Respondents who had experienced bullying, had fewer friends, and had skipped or been suspended from school were more likely to be depressed.

\section{Depression Disparity between Schools}

Variance between schools. Table 2 provides the estimated variance of school intercepts in each of the four multilevel modelling steps. The variance between schools in the null model is 0.16 , indicating that the prevalence of depression significantly differed between schools $(p<0.0001)$. Adding demographic variables and family structure into the model reduced the variance between schools to 0.10 , which was a $37.5 \%$ reduction from the null model. This indicates that gender, cultural status, and family structure contributed to $37.5 \%$ of the observed variance in depression between schools. In the third step, three factors were added to the model separately. The variance between schools did not change much in models with physical activity and bullying, but it dropped to 0.04 when school refusal behaviour covariates were added, indicating that school refusal behaviour contributed to another $37.5 \%$ of the variance.

Significant effects of individual-level variables. Table 3 provides the variables that were significantly associated with depression in the final model. Cultural status, physical activity level (KKD), off-school exercise, physical bullying, verbal bullying, and being suspended from school were not statistically significant through the multilevel modelling process. 
Table 2

Estimated Variance of School Intercepts

\begin{tabular}{cccccc}
\hline Model 1 & Model 2 & \multicolumn{3}{c}{ Model 3 } & Model 4 \\
\cline { 3 - 5 } $\begin{array}{c}\text { School random } \\
\text { effect }\end{array}$ & $\begin{array}{c}\text { Demographic \& } \\
\text { family structure }\end{array}$ & $\begin{array}{c}\text { Physicial } \\
\text { activity }\end{array}$ & Bullying & $\begin{array}{c}\text { School } \\
\text { performance }\end{array}$ & Deprivation \\
0.16 & 0.10 & 0.11 & 0.10 & 0.04 & 0 \\
\hline
\end{tabular}

Children who had a very good relationship with their parents were more likely to report being depressed in the multilevel model ( $\mathrm{OR}=2.59 ; 95 \% \mathrm{CI}$ : 1.59-4.24). In terms of school refusal behaviours, students who sometime felt like outsiders (OR $=0.71 ; 95 \%$ CI: $0.45-1.13)$, those who had skipped school (OR $=$ 4.73; 95\% CI: $2.75-8.14)$, and those who had been treated badly at school (OR $=1.93 ; 95 \%$ CI: $1.49-2.50)$ were more likely to suffer from depression.

Significant effects of school-level variables. Students who attended schools deemed moderate in terms of material deprivation were 2.04 times more likely to be depressed than those attending schools deemed minimum $(\mathrm{OR}=2.04,95 \% \mathrm{CI}$ : $1.53-2.72)$. Social deprivation was found to have no association with depression $(\mathrm{OR}=1.23$ for moderate compared to low; $\mathrm{OR}=0.86$ for high compared to low).

Interaction terms. Interactions were observed in our study, which indicated the association between depression and some of the variables were stratified by other variables. Specifically, the association between BMI and depression was modified by family structure and parents' educational level. In single-parent families, the risk of depression was 2.48 times higher for overweight children than for normal-weight children. Among students whose parents had a lower educational level, overweight students were 2.02 times more likely to be depressed. The association between electronic bullying and depression was also modified by gender. Girls were vulnerable to depression no matter how often they were being bullied, but boys suffered from a depressed mood only when being bullied often ( $p=0.97$ for sometimes vs. never; $p=0.01$ for often vs. never). Finally, depressed students were 4.71 times more likely to skip school, but this happened only in schools with minimum material deprivation level.

\section{DISCUSSION}

This study focused on the prevalence of depression among children in Saskatoon elementary schools, particularly the association between depression and both individual-level factors and school-level factors. Our study showed that covariates like gender, relationship with parents, electronic and social bullying, feeling like an outsider at school, skipping school, and being treated badly at school were significantly associated with depression. Covariates that contributed to the differences in depression between schools were demographic characteristics and school refusal behaviour covariates. 
Table 3

Final Multilevel Logistic Regression Model Showing All Significant Correlates (Individual Level) Associated with Depression, Saskatoon, 2008-9

\begin{tabular}{ccc}
\hline Variable & Odds Ratio & $\begin{array}{c}95 \% \\
\text { Confidence } \\
\text { Intervals }\end{array}$ \\
\hline
\end{tabular}

\section{Demographic characteristics}

Gender

Female

Male

$\begin{array}{ccc}1 & - & - \\ 0.70 & 0.54-0.91 & 0.007\end{array}$

Family background

Family structure

$0.54-0.91$

0.007

Both mother and father

Single parent

Other

Parents' education level

At least one is high school or less

Both college or university

Relationship with parents

Not very good

Very good

1

Physical activity

BMI

Normal

Overweight/obese

\section{Bullying}

Social bullying

Never

Once or twice

Many times a week

Electronic bullying

Never

Once or twice

Many times a week

\section{Social performance}

Have many friends

False

Sometimes true

True

Get along with others easily

False

Sometimes true

True
1.07

2.39

1

3.28

1

2.59

1

1.73

1

1.11

1.75

1

3.18

2.62

$1.07-2.80$

0.03

$0.77-1.49$

1.13-5.07

0.69

0.02

$1.07-10.06$

0.04

0.0001

$1.59-4.24$

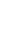

(1)

$0.83-1.48$

$1.13-2.69$

0.49

0.007

1.97-5.14

$1.04-6.59$

$<0.0001$

0.04

$\begin{array}{ccc}1 & - & - \\ 0.74 & 0.38-1.45 & 0.38 \\ 0.47 & 0.26-0.88 & 0.02 \\ & & - \\ 1 & - & 0.33 \\ 1.62 & 0.62-4.26 & 0.94\end{array}$


Table 3

(continued)

\begin{tabular}{|c|c|c|c|}
\hline Variable & Odds Ratio & $\begin{array}{c}95 \% \\
\text { Confidence } \\
\text { Intervals }\end{array}$ & $p$-value \\
\hline \multicolumn{4}{|l|}{ Feel like an outsider } \\
\hline All the time & 1 & - & - \\
\hline Sometimes & 0.71 & $0.45-1.13$ & 0.15 \\
\hline Rarely/never & 0.26 & $0.17-0.42$ & $<0.0001$ \\
\hline \multicolumn{4}{|l|}{ Skipped school } \\
\hline Never & 1 & - & - \\
\hline Reported & 4.71 & $2.75-8.14$ & $<0.0001$ \\
\hline \multicolumn{4}{|l|}{ Been treated badly at school } \\
\hline Never & 1 & - & - \\
\hline Reported & 1.93 & $1.49-2.50$ & $<0.0001$ \\
\hline \multicolumn{4}{|l|}{ Contextual variables } \\
\hline \multicolumn{4}{|l|}{ Material deprivation } \\
\hline Low & 1 & & \\
\hline Moderate & 2.04 & $1.53-2.72$ & $<0.0001$ \\
\hline High & 1.26 & $0.61-2.60$ & 0.53 \\
\hline \multicolumn{4}{|l|}{ Social deprivation } \\
\hline Low & 1 & - & - \\
\hline Moderate & 1.23 & $0.94-1.61$ & 0.13 \\
\hline High & 0.86 & $0.51-1.45$ & 0.58 \\
\hline \multicolumn{4}{|l|}{ Interactions } \\
\hline \multicolumn{4}{|l|}{ Family structure x BMI } \\
\hline Single parent $\mathrm{x}$ Overweight & 2.48 & $1.43-4.28$ & 0.0012 \\
\hline \multicolumn{4}{|l|}{ Parents' educational level x BMI } \\
\hline At least one high school x Overweight & 2.02 & $1.16-3.51$ & 0.01 \\
\hline \multicolumn{4}{|l|}{ Electronic bullying x Gender } \\
\hline Once or twice x Female & 3.18 & $1.97-5.14$ & $<0.0001$ \\
\hline Many times a week $x$ Female & 2.62 & $1.04-6.59$ & 0.04 \\
\hline Many times a week x Male & 3.89 & $1.38-10.95$ & 0.01 \\
\hline \multicolumn{4}{|c|}{ Get along with others $x$ Parents' educational level } \\
\hline True $\mathrm{x}$ Both college & 0.27 & $0.12-0.63$ & 0.002 \\
\hline \multicolumn{4}{|l|}{ Material deprivation x Skipped school } \\
\hline Minimum x Reported & 4.71 & $2.75-8.14$ & 0.0003 \\
\hline
\end{tabular}


We found depressed mood was more common among girls than boys. Whether a student was Aboriginal or Caucasian was not a significant factor in the multilevel model. Our finding was consistent with the previous findings from Saskatoon Health Region, which showed that Aboriginal cultural status was not associated with depressed mood after controlling for other covariates (Lemstra et al., 2008).

An interesting finding in our study was that those who reported having a very good relationship with their parents had a significantly higher prevalence of depressed mood. To determine whether selection bias could explain this association, we compared depression prevalence between children who responded to this question and those who did not. There was no significant difference in depression prevalence between responders $(22.4 \%)$, and non-responders $(20.9 \%)$. It is possible that adolescents who report a "very good" relationship with their parents may experience subtle or not so subtle pressure to achieve more in school, sports, or other extracurricular activities, resulting in some level of stress and depression/anxiety. On the other hand, it is possible that those adolescents who are having difficulty at school, or generally outside of the home, may turn to their parents for support and comfort. Given that this study is cross-sectional it is difficult to say in which direction these associations work. These hypotheses need to be tested in subsequent studies.

Our study revealed that BMI had a significant association with depression but physical activity was not associated with depression. Overweight children were more likely to be depressed. A previous study indicated that the relative risk of depression is much higher for overweight/obese boys (Tomson, Pangrazi, Friedman, \& Hutchison, 2003); however, this study showed no significant relationship between BMI and depression among girls, which revealed an interaction between BMI and gender. We found BMI by gender interaction was not significant. However, BMI by family structure and BMI by parental educational level interactions were significant in our study.

In our study, we found that electronic bullying was more harmful than any other types of bullying in terms of a negative effect on children's mental health status. Girls were more sensitive to electronic bullying and experienced a relatively higher prevalence of depression than boys when victims of bullying. Sixty per cent of respondents in our study reported no school refusal behaviours. However, among those who did report school refusal behaviours, the experience of feeling like an outsider, having skipped school, and having been treated badly at school were three covariates significantly associated with depression. Children who had school refusal behaviour problems had a higher prevalence of depression in our study. This result was consistent with other studies (Hersov, 1960; Kearney, 1993, 2007).

For school-level effect, the overall effect of material deprivation was significant, while social deprivation was not. However, it was still included in the final multilevel model because we wanted to control for school-level contextual effects. Our study indicated that mental health disparity exists between schools, which corroborated our assumption that depression in school children varied between schools. Of all the individual-level factors, school refusal behaviour variables were the main factors that substantially contributed to the observed differences in depression prevalence between schools.

The Student Health Survey has been an important tool for decision-making in Saskatoon Health Region, informing the development and delivery of health promotion programming in schools, funding decisions, and the re-allocation of resources (Scott, Cushon, \& Neudorf, 2012). The results of this study will be used to further inform programming and targeting. The Mental Health Commission of Canada recently stated 
that mental health promotion programs in a school setting are important for prevention and for building resilience among young students (Mental Health Commission of Canada, 2012). In addition, targeting entire schools or classrooms has obvious benefits because it reduces the stigma attached to receiving mental health services (Shochet \& Ham, 2004). Broadly delivered programs also address the issue of most children and youth not accessing mental health services since it is estimated that only one in four children and youth who are experiencing mental health issues seek out and receive services (Mental Health Commission of Canada, 2012).

According to our study, one of the key variables to take into consideration when selecting schools for mental health promotion programming in Saskatoon Health Region is material deprivation. Also, since depression was more common among girls than boys in our study, a finding that has been validated in many other studies (Afifi, Enns, Cox, \& Martens, 2005; Garber, 2006; Mazza, Fleming, Abbott, Haggerty, \& Catalano, 2010), gender considerations should also be a component of programming. Interactions between overweight/obese status and gender, along with bullying and gender, are further potential considerations when aiming to prevent depression. While some issues might be common across contexts such as gender differences in depression rates, there might be context-specific issues that require some investigation when targeting and developing programming.

Our study had limitations. This self-report survey could have suffered from selection bias as students who participated in the survey might differ from those who did not participate in many aspects such as demographic characteristics, socio-economic status, cultural status, and so on. This bias could affect the external validity of our study. Information bias might have also occurred because of the sample's young age, as children may have misclassified themselves into the wrong group. A further limitation is that although information on family income of participants has been shown to be an essential component of SES when exploring health disparity (Wu, Noh, Kaspar, \& Schimmele, 2003), this information was not available in our study. There may be other variables not accounted for in the analysis that may distort the relationship with depression. Potential confounders such as genetic factors were not available, which limits our study. In addition, since this is a cross-sectional study and we could only infer associations, a cohort study would be needed to understand the causality between students' depression and their demographic, physical activity, school-level, and genetic factors.

Our study had several strengths. This study used a dataset from a survey conducted by Saskatoon Health Region, which has several advantages. This study had a large sample size compared to other studies. A previous study that evaluated children's school refusal behaviours and depression had only 26 children as the whole sample size (Bernstein \& Garfinkel, 1986). Another study examined 143 children's school experiences and mental health status, and was considered to be "a study with large clinical sample" (Kearney \& Albano, 2004). Another strength was that our study took school-level variables into account and conducted multilevel analysis. There are few studies focused on school-level or contextual-level deprivation; thus our study was unusual in this regard and provided more accurate analysis. This multilevel approach allowed us to explore the data at both the individual and the school level. By obtaining school-level information, we were able to better describe the characteristics of schools that account for depression disparities. This is a unique approach to studying children's mental health status. 


\section{CONCLUSION}

In summary, depression among Saskatoon children deserves greater attention. These findings will provide Saskatoon Health Region with evidence to inform the programming and the targeting of interventions in terms of the factors identified in this study. The study was unique as it considered multilevel analysis by taking school-level variables into account. Depressed mood was associated with gender, family structure, relationship with parents, electronic bullying, and negative experiences at school such as feeling like an outsider at school, skipping school, and being treated badly at school. There was disparity in depression among schools, and students' social lives and their experiences at school were the factors contributing most significantly to this disparity.

\section{REFERENCES}

Afifi, T.O., Enns, M.W., Cox, B.J., \& Martens, P.J. (2005). Investigating health correlates of adolescent depression in Canada. Canadian Journal of Public Health, 96(6), 427-431.

Anderman, E. (2002). School effects on psychological outcomes during adolescence. Journal of Educational Psychology, 94, 795-809.

Arseneault, L., Walsh, E., Trzesniewski, K., Newcombe, R., Caspi, A., \& Moffitt, T.E. (2006). Bullying victimization uniquely contributes to adjustment problems in young children: A nationally representative cohort study. Pediatrics, 118, 130-138.

Bernstein, G.A., \& Garfinkel, B.D. (1986). School phobia: The overlap of affective and anxiety disorders. Journal of the American Academy of Child Psychiatry, 25, 235-241.

Boulton, M.J., \& Underwood, K. (1992). Bully/victim problems among middle school children. British Journal of Educational Psychology, 62, 73-87.

Boyce, W. (2004). Young people in Canada: Their health and well-being. Health Behaviour in School-Aged Children Survey 2001-2. Ottawa, ON: Health Canada. Retrieved from http://www.phac-aspc.gc.ca/hp-ps/dca-dea/publications/ hbsc-2004/pdf/hbsc_report_2004_e.pdf

Boyle, P.J., Gatrell, A.C., \& Duke-Williams, O. (2001). Do area level population change, deprivation and variations in deprivation affect individual-level self-reported limiting long-term illness? Social Science \& Medicine, 53, $795-799$.

Canadian Public Health Association \& National Crime Prevention Strategy. (2007). CPHA Safe School Study. Retrieved from http://acsp.cpha.ca/antibullying/english/backinfo/Safe_School_Study_Final.pdf

Centers for Disease Control and Prevention. (2010). Clinical growth charts. Retrieved from http://www.cdc.gov/ growthcharts/clinical_charts.htm

Cole, D.A., Martin, J., Peeke, L., Seroczynski, A., \& Fier, J. (1999). Children's over- and underestimation of academic competence: A longitudinal study of gender differences, depression, and anxiety. Child Development, 70, 459-473.

Craig, W.M. (1998). The relationship among bullying, victimization, depression, anxiety, and aggression in elementary school children. Personality and Individual Differences, 24, 123-130.

Crick, N.R., \& Bigbee, M.A. (1998). Relational and overt forms of peer victimization: A multiinformant approach. Journal of Consulting and Clinical Psychology, 66, 337-347.

Ellonen, N., Kaariainen, J., \& Autio, V. (2008). Adolescent depression and school social support: A multilevel analysis of a Finnish sample. Journal of Community Psychology, 36(4), 552-567.

Garber, J. (2006). Depression in children and adolescents: Linking risk research and prevention. American Journal of Preventive Medicine, 31, S104-125.

Ge, X., Lorenz, F.O., Conger, R., Elder, G.H., \& Simons, R.L. (1994). Trajectories of stressful life events and depressive symptoms during adolescence. Developmental Psychology, 30(4), 467-483.

Hawker, D.S., \& Boulton, M.J. (2000). Twenty years' research on peer victimization and psychosocial maladjustment: A meta-analytic review of cross-sectional studies. Journal of Child Psychology and Psychiatry, 41, 441-455.

Health Canada. (2003). A statistical profile on the health of First Nations in Canada for the year 2000. Ottawa: Health Canada, First Nations and Inuit Health Branch. 
Hersov, L.A. (1960). Persistent non-attendance at school. Journal of Child Psychology and Psychiatry, 1, $130-136$.

Hodges, E.V., \& Perry, D.G. (1999). Personal and interpersonal antecedents and consequences of victimization by peers. Journal of Personality and Social Psychology, 76, 677-685.

Jones, K., \& Duncan, C. (1995). Individuals and their ecologies: Analysing the geography of chronic illness within a multilevel modelling framework. Health and Place, 1(1), 27-40.

Kearney, C.A. (1993). Depression and school refusal behaviour: A review with comments on classification and treatment. Journal of School Psychology, 31, 267-279.

Kearney, C.A. (2007). School absenteeism and school refusal behaviour in youth: A contemporary review. Clinical Psychology Review, 28, 451-471.

Kearney, C.A., \& Albano, A.M. (2004). The functional profiles of school refusal behavior: Diagnostic aspects. Behavior Modification, 28, 147-161.

Kim-Cohen, J., Caspi, A., Moffitt, T.E., Harrington, H., Milne, B.J., \& Poulton, R. (2003). Prior juvenile diagnoses in adults with mental disorder: Developmental follow-back of a prospective-longitudinal cohort. Archives of General Psychiatry, 60, 709-717.

Kobetz, E., Daniel, M., \& Earp, J.A. (2003). Neighborhood poverty and self-reported health among low-income, rural women, 50 years and older. Health \& Place, 9, 263-271.

Lemstra, M., \& Neudorf. C. (2008). Health disparity in Saskatoon: Analysis to intervention. Saskatoon, SK: Saskatoon Health Region.

Lemstra, M., Neudorf, C., Mackenbach, J., Arcy, C., Scott, C., Kershaw, T., \& Nannapaneni, U. (2008). Risk indicators for depressed mood in youth: Limited association with Aboriginal cultural status. Paediatrics \& Child Health, 13(4), 285-290.

Malmström, M., Johansson, S.E., \& Sundquist, J. (2001). A hierarchical analysis of long-term illness and mortality in socially deprived areas. Social Science \& Medicine, 53, 265-275.

Martinsen, E.W. (1990). Benefits of exercise for the treatment of depression. Sports Medicine, 9(6), 380-389.

Mental Health Commission of Canada. (2012). Changing directions, changing lives: The mental health strategy for Canada. Calgary, AB: Author.

Mazza, J.J., Fleming, C.B., Abbott, R.D., Haggerty, K.P., \& Catalano, R.F. (2010). Identifying trajectories of adolescents' depressive phenomena: An examination of early risk factors. Journal of Youth and Adolescence, 39, $579-593$.

Nansel, T.R., Overpeck, M., Pilla, R.S., Ruan, W.J., Simons-Morton, B., \& Scheidt, P. (2001). Bullying behaviours among US youth: Prevalence and association with psychosocial adjustment. Journal of the American Medical Association, 285, 2094-2100.

National Institute of Mental Health. (1990). Research on children and adolescents with mental, behavioural, and developmental disorders. DHHS Publication No. ADM 90-1659. Washington, DC: U.S. Government Printing Office.

Olweus, D. (1978). Aggression in the schools: Bullying and whipping boys. Washington, DC: Hemisphere.

Opdenakker, M.-C., \& Van Damme, J. (2001). Relationship between school composition and characteristics of school process and their effect on mathematics achievement. British Educational Research Journal, 27, 407-432.

Paluska, S.A., \& Schwenk, T.L. (2000). Physical activity and mental health. Sports Medicine, 29(3), $167-180$.

Pampalon, R., \& Raymond, G. (2000). A deprivation index for health and welfare planning in Quebec. Chronic Diseases in Canada, 21, 104-113.

Pampalon, R., Hamel, D., Gamache, P., \& Raymond, G. (2009). A deprivation index for health planning in Canada. Chronic Diseases in Canada, 29(4), 178-191.

Poulin, C., Hand, D., \& Boudreau, B. (2005). Validity of a 12-item version of the CES-D used in the National Longitudinal Study of Children and Youth. Chronic Diseases in Canada, 26(2-3), 65-72.

Ross, C.E. (2000). Neighborhood disadvantage and adult depression. Journal of Health and Social Behaviour, 41(2), 177-187.

Sallis, J.F. (1996). Sports for all or physical activity for all. Lancet, 347, 1779.

Scott, C., Cushon, J., \& Neudorf, C. (2012). The Student Health Survey in 2006/2007 and 2008/2009: A comprehensive report. Saskatoon, SK: Saskatoon Health Region.

Shochet, I.M., \& Ham, D. (2004). Universal school-based approaches to preventing adolescent depression: Past findings and future directions of the Resourceful Adolescent Program. International Journal of Mental Health Promotion, $6(3), 17-25$. 
Stafford, M., \& Marmot, M. (2003). Neighbourhood deprivation and health: Does it affect us equally? International Journal of Epidemiology, 32, 357-366.

Stagman, S., \& Cooper, J.L. (2010). Children's mental health: What every policymaker should know. New York, NY: Columbia University, Mailman School of Public Health, National Center for Children in Poverty.

Statistics Canada. (2002). National Longitudinal Survey of Children and Youth, cycle 5, Microdata user guide. Ottawa, ON: Human Resources Development Canada. Retrieved from http://www.statcan. ca/english/freepub/89F0077XIE/ free.htm

Tomson, L., Pangrazi, R., Friedman., G., \& Hutchison. N. (2003). Childhood depressive symptoms, physical activity and health related fitness. Journal of Sport \& Exercise Psychology, 25, 419-439.

Trautwein, U., Köller, O., Schmitz, B., \& Baumert, J. (2002). Do homework assignments enhance achievement? A multilevel analysis in 7th grade mathematics. Contemporary Educational Psychology, 27, 26-51.

Tuma, J.M. (1989). Mental health services for children: The state of the art. American Psychologist, 44, 188-199.

Wade, T., Cairney, J., \& Pevalin, D. (2002). Emergence of gender differences in depression during adolescence: National panel results from three countries. Journal of the American Academy of Child and Adolescent Psychiatry, 41, 190-198.

Wichstrom, L. (1999). The emergence of gender difference in depressed mood during adolescence: The role of intensified gender socialization. Developmental Psychology, 35, 232-245.

Wolke, D., Woods, S., Stanford, K., \& Schulz, H. (2001). Bullying and victimization of primary school children in England and Germany: Prevalence and school factors. British Journal of Psychology, 92, 673-696.

Wong, S.L., Leatherdale, S.T., \& Manske, S.R. (2006). Reliability and validity of a school-based physical activity questionnaire. Medicine \& Science in Sports and Exercise, 38(9), 1593-1600.

Wu, Z., Noh, S., Kaspar, V., \& Schimmele, M. (2003). Race, ethnicity and depression in Canadian society. Journal of Health and Social Behavior, 44(3), 426-441. 